\title{
In vitro and in vivo anti-allergic effects of an extract of a traditional Chinese medicine preparation
}

\author{
Li Li', Xiao-yue Wang ${ }^{1}$, Hong Meng ${ }^{1}$, Guang-rong Liu², Chang Liu ${ }^{1}$ and Yin-Mao Dong ${ }^{1 *}$
}

\begin{abstract}
Background: The present research was conducted to investigate the in vivo and in vitro anti-allergic activity of a traditional Chinese medicine formulation comprising Ampelopsis grossedentata, Saposhnikovia divaricata, Sophora flavescens, Angelica sinensis, Ophiopogon japonicus, and Cornus officinalis.

Methods: The hyaluronidase inhibitory activity of an active extract of this formulation (AEF) was evaluated in vitro. In vivo studies were conducted to explore its effects on pruritus, the anti-dinitrophenyl (DNP) IgE-induced passive cutaneous anaphylaxis (PCA) reaction, and skin repair, in order to investigate the therapeutic effects of AEF in allergic skin reactions. The inhibitory effects of the main active ingredient of AEF (dihydromyricetin (DMY)) on the pro-inflammatory cytokines, interleukin (IL)-6 and IL-8 in phorbol-12-myristate 13-acetate plus the calcium ionophore A23187 (PMACI)-stimulated KU812 cells, were measured using enzyme-linked immunosorbent assays.

Results: An in vivo test showed that AEF produced significant inhibition of pruritus, PCA reaction, and skin barrier dysfunction. The main chemical DMY significantly decreased the PMACl-induced increase in pro-inflammatory cytokines, including IL-6 and IL-8 in KU812 cells. The in vivo anti-allergy effects on the skin may have resulted from reduced levels of IL-6 and IL-8.

Conclusions: These findings indicated that the formulation and one of its constituents, DMY, may exert excellent anti-inflammatory effects, with applications in the treatment of skin allergic reactions including pruritus, diffuse redness, and swelling.
\end{abstract}

Keywords: Anti-allergic activity, Traditional Chinese medicine formulation, Dihydromyricetin, KU812 cells, Interleukin-6, Interleukin-8

\section{Background}

In recent years, increased air pollution and dietary changes have increased the prevalence of sensitive skin, associated with allergic reactions and inflammation. This problem affects human health worldwide (Farage et al. 2013; Xu et al. 2012). Pharmacological options for the treatment of allergic diseases are sometimes associated with side effects and drug resistance (Liu et al. 2014). Research into naturally occurring anti-allergy agents present in plants and traditional Chinese medicine (TCM) formulations is therefore currently underway,

\footnotetext{
* Correspondence: ymdong2008@163.com

${ }^{1}$ Beijing Key Laboratory of Plant Resources Research and Development, Beijing Technology and Business University, Beijing 100048, People's Republic of China

Full list of author information is available at the end of the article
}

with the aim of identifying effective treatments with fewer side effects (Jung et al. 2012).

The stems and leaves of Ampelopsis grossedentata provide a traditional Chinese herbal tea named Rattan, which was considered to be cool and sweet and was used to clear heat and dredge meridians. Modern pharmacological studies have shown that $A$. grossedentata has antioxidant, anti-inflammatory, and antibacterial activities (Kou and Chen 2012). The main chemical constituent of $A$. grossedentata, dihydromyricetin (DMY), is known to have a broad range of biological functions including hypoglycemic, antioxidant, anti-inflammatory, antitumor, hepatoprotective, and neuroprotective effects. These reported effects have led to increased research into the bioactivity of DMY over the last decade, leading 
to improved understanding of its pharmacological effects and their underlying mechanisms (Kou and Chen 2012).

We previously screened out A. grossedentata, Saposhnikovia divaricata, Sophora flavescens, Angelica sinensis, Ophiopogon japonicus, and Cornus officinalis from a large number of herbs used in TCMs, including for hyaluronidase inhibition, antioxidant effects (radical scavenging test using 1,1-diphenyl-2-picrylhydrazyl (DPPH)), and antibacterial activities. In order to obtain a formulation with better anti-allergic properties, the ratios of the six herbs and its extraction method were further optimized by the single factor and response surface methodology (Lin and Ji 2013) directed by hyaluronidase inhibition test. An active extract obtained from the formulation (AEF) was used to do further anti-allergic evaluation in vitro and in vivo.

In the present study, the effects on pruritus, antidinitrophenyl (DNP) IgE-induced passive cutaneous anaphylaxis (PCA), and skin repair of AEF were evaluated in vivo. Human leukemia KU812 cells stimulated with phorbol 12-myristate 13-acetate (PMA) and the calcium ionophore, A23187, were exposed to DMY in order to evaluate the effects of this compound on levels of the pro-inflammatory cytokines, interleukin (IL)-6 and IL-8. The KU812 myeloid precursor cell line, which was originally established from a patient with chronic myelogenous leukemia, has been shown to be a suitable model for studying the activation and degranulation of human mast cells (Rasheed et al. 2009). These studies indicated that $A$. grossedentata and related TCM formulations have the potential to provide raw materials for the production of anti-allergy medicines and cosmetics.

\section{Methods}

\section{Chemicals and reagents}

Anti-DNP IgE, DNP-human serum albumin (HSA), Evans blue, histamine phosphate, hyaluronidase, $p$ dimethylaminobenzaldehyde, fluocinonide ointment, disodium cromoglycate (DSCG), A23187, and PMA were purchased from Sigma (St. Louis, MO, USA). KU812 cells were purchased from the Shanghai Institute cell library. Iscove's Modified Dulbecco's Medium (IMDM), penicillin, and streptomycin were purchased from Gibco (Invitrogen Corporation, Carlsbad, CA, USA). Fetal bovine serum (FBS) was purchased from HyClone (Logan, UT, USA). Cytokine-specific enzyme-linked immunosorbent assay (ELISA) kits were purchased from R\&D Systems (USA). DMY was purchased from Shanghai Tauto Biotech. Co., Ltd. (Shanghai, China), and was determined to be greater than $98 \%$ pure by highperformance liquid chromatography (HPLC) analysis. Other reagents used were of analytical grade.

\section{Sample preparation}

A. grossedentata, S. divaricata, S. flavescens, A. sinensis, O. japonicus, and $C$. officinalis were purchased from the Beijing Tongrentang Co., Ltd. (Beijing, China). All herbs were authenticated by Professor Y. Peng, a medical botanist at the Institute of Medicinal Plant Development (IMPLAD), Chinese Academy of Medical Science (CAMS), Beijing, China. The optimized ratio of the herbs was determined to be $3: 2: 2: 1.7: 1.2: 1.2$, using a Design-Expert regression model directed by hyaluronidase inhibitory activity. The formulation (100 g) was extracted by thermal recycling with $70 \%$ ethanol (1:13) for $140 \mathrm{~min}$ at $68{ }^{\circ} \mathrm{C}$ and filtered. The AEF was concentrated in a rotary vacuum evaporator, lyophilized, and stored at $-20{ }^{\circ} \mathrm{C}$ until use.

The AEF was standardized based on its DMY content. Chromatographic separation was carried out on an Agilent 1260 LC series system (Agilent Technologies, Palo Alto, CA, USA) equipped with online vacuum degasser, quaternary pump, autosampler, temperature-controlled column compartment, and a diode array detector. Agilent Technologies ChemStation software for LC (B.02.01) was used. Chromatographic separation was achieved on an Agilent RP C18 $(150 \mathrm{~mm} \times 4.6 \mathrm{~mm}, 5 \mu \mathrm{m})$ using a mobile phase consisting of water to acetic acid (99.8:0.1, v/v) (A) and methanol (B). The gradient program consisted of $60 \%$ (B) for $0-30 \mathrm{~min}$. The flow rate was $0.5 \mathrm{~mL} / \mathrm{min}$, and the column temperature was set to $25{ }^{\circ} \mathrm{C}$. The detection wavelength was $290 \mathrm{~nm}$. DMY was detected at around $5.6 \mathrm{~min}$ in this system. The DMY content of the AEF was $10.25 \pm 0.83 \mathrm{mg} / \mathrm{g}(n=3)$.

\section{Cell culture}

KU812 cells were grown in IMDM culture medium supplemented with $10 \%$ heat-inactivated FBS and $1 \%$ penicillin-streptomycin at $37{ }^{\circ} \mathrm{C}$ in $5 \% \mathrm{CO}_{2}$. KU812 cells were pre-treated with the $\operatorname{AEF}(50,200$, or $300 \mu \mathrm{g} / \mathrm{mL})$ for $2 \mathrm{~h}$ prior to stimulation with $40 \mathrm{nM}$ PMA and $1 \mu \mathrm{M}$ A23187 for different periods of time. The AEF was diluted in nuclease-free double-filtered distilled water, whereas PMA and A23187 were dissolved in DMSO.

\section{Animals}

Hartley guinea pigs $(250 \pm 10 \mathrm{~g})$ and Sprague-Dawley rats (200-250 g) were obtained from the Vital River Laboratory Animal Technology Co. Ltd. (Beijing, China). These animals were housed under standard conditions with a 12/12-h light/dark cycle at a temperature of $22 \pm 1{ }^{\circ} \mathrm{C}$ with $55 \pm 10 \%$ humidity and were given standard laboratory feed (Beijing Jinmuyang Laboratory Animals, Inc., Beijing, China) and water ad libitum. The animal certification number was SCXK (Jing) 2010-0001. Animal protocols were developed in 
accordance with the institution's guidelines for the care and use of laboratory animals and were approved by the local Animal Care and Use Committee.

\section{Inhibition of hyaluronidase activity}

Hyaluronidase inhibition was determined by measuring the amount of $\beta$ - $\mathrm{N}$-acetylglucosamine formed from sodium hyaluronate, using a spectrophotometer (Kakegawa 1992). Bovine hyaluronidase $(500 \mu \mathrm{L}$ of 7420 units $/ \mathrm{mL}$ in $0.1 \mathrm{M}$ acetate buffer; $\mathrm{pH}$ 5.6) was mixed with $100 \mu \mathrm{L}$ calcium chloride $(0.25 \mathrm{mM})$ and then incubated in a water bath at $37^{\circ} \mathrm{C}$ for $20 \mathrm{~min}$. The indicated test sample was added in a volume of $500 \mu \mathrm{L}$, and the mixture was incubated in a water bath at $37^{\circ} \mathrm{C}$ for $20 \mathrm{~min}$, after which sodium hyaluronate $(500 \mu \mathrm{L}$ of $0.5 \mathrm{mg} / \mathrm{mL}$ in $0.1 \mathrm{M}$ acetate buffer; pH 5.6) was added. After a 30-min incubation in a water bath at $37{ }^{\circ} \mathrm{C}, 100 \mu \mathrm{L}$ of $0.4 \mathrm{M}$ sodium hydroxide was added to stop the reaction, and the mixture was placed in an ice-water bath for $5 \mathrm{~min}$. Next, $500 \mu \mathrm{L}$ acetylacetone was added, and the mixture was incubated in boiling water for $30 \mathrm{~min}$ to produce a chromogenic reaction. After cooling to $25{ }^{\circ} \mathrm{C}, 1.0 \mathrm{~mL}$ of $p$-dimethylaminobenzaldehyde solution was added to the reaction mixture for $20 \mathrm{~min}$ at $25^{\circ} \mathrm{C}$. The optical density of the reaction mixture was measured at $555 \mathrm{~nm}$ using a microplate reader (RT-6000; Leidu, Shenzhen, China). All determinations were performed in triplicate.

\section{Measurement of pruritus}

Hartley guinea pigs $(250 \pm 10 \mathrm{~g})$ were randomly divided into four groups with eight animals/group; these groups consist of model control group (physiological saline, 100 $\mathrm{mg} / \mathrm{cm} 2$ ), positive control group (DSCG, $100 \mathrm{mg} / \mathrm{cm}^{2}$ ), low dosage experimental group (AEF, $50 \mathrm{mg} / \mathrm{cm}^{2}$ ), middle dosage experimental group (AEF, $100 \mathrm{mg} / \mathrm{cm}^{2}$ ) and high dosage experimental group (AEF, $150 \mathrm{mg} / \mathrm{cm}^{2}$ ) applied to shaved dorsal skin sites $\left(2 \mathrm{~cm}^{2}\right)$ on their back right feet for 2 days. On the third day, the samples were applied to the shaved sites for $10 \mathrm{~min}$, followed by $0.05 \mathrm{~mL}$ of increasing concentrations of histamine phosphate $(0.01,0.02,0.03,0.04,0.05,0.06,0.07,0.08,0.09$, or $0.1 \%$ ), each of which was dripped onto the test site for $3 \mathrm{~min}$. The scratching behavior induced by histamine phosphate was recorded, and the itch threshold was the level required to produce itching ( $\mathrm{Hu}$ and Zhong 2013).

\section{Induction of the PCA reaction}

Sprague-Dawley rats (200-250 g) were divided into six groups with eight rats/group: the untreated control group, the model group (distilled water, $100 \mathrm{mg} / \mathrm{cm}^{2}$ ), the positive control group (fluocinonide ointment, $\left.50 \mathrm{mg} / \mathrm{cm}^{2}\right)$, and the high AEF $\left(100 \mathrm{mg} / \mathrm{cm}^{2}\right)$, middle $\operatorname{AEF}\left(50 \mathrm{mg} / \mathrm{cm}^{2}\right)$, and low AEF $\left(25 \mathrm{mg} / \mathrm{cm}^{2}\right)$ dose groups. Each group had the appropriate treatment applied to the skin at three dorsal skin injection sites, which were outlined with a water-insoluble red marker. One hour later, the PCA reaction was generated by sensitizing the skin with an intradermal injection of $0.5 \mu \mathrm{g}$ anti-DNP IgE into each of the sites. After $48 \mathrm{~h}$, this was followed by a tail vein injection of $100 \mu \mathrm{g}$ DNP-HSA in phosphate-buffered saline containing $4 \%$ Evans blue. The rats were sacrificed $30 \mathrm{~min}$ after the administration of DNP-HSA. The skin at the injection site was removed for measurement of the pigment area. The amount of dye was determined by colorimetry after extraction using a 1:1 mixture of acetone and physiological saline (Shin et al. 2004). The absorbance of the skin extract was measured at $620 \mathrm{~nm}$ in a microplate reader (RT-6000; Leidu), and the amount of dye was calculated using an Evans blue calibration curve.

\section{Evaluation of skin repair activity}

Hartley guinea pigs $(250 \pm 10 \mathrm{~g})$ were randomly divided into five groups with eight animals/group: a blank control group (physiological saline), a model control group, and groups exposed to different dosages of AEF. The hair on the back of the neck of each guinea pig was shaved the day before the experiment to expose about $2 \mathrm{~cm}^{2}$ skin. Each group (except for the blank control group) had $150 \mu \mathrm{L}$ acetone to ether (1:1) solution dripped onto the shaved skin. Test samples $\left(0.1 \mathrm{~mL} / \mathrm{cm}^{2}\right)$ were smeared onto the shaved skin; $0.1 \mathrm{~mL} / \mathrm{cm}^{2}$ distilled water was applied to the model control group. Treatments were administered twice daily for five consecutive days. On the fifth day, the skin moisture loss of the shaved skin was tested 20 min after sample administration. Protection rates (\%) were calculated for each study group.

\section{Cytokine ELISAs}

Levels of IL-6 and IL- 8 in the culture medium were quantified by specific sandwich ELISAs. Briefly, KU812 cells were stimulated with PMA (40 nM) plus A23187 $(1 \mu \mathrm{M})$ for $12 \mathrm{~h}$, with or without pre-treatment with AEF (Rasheed et al. 2009). The ELISAs were performed using the culture supernatants, in accordance with the manufacturer's instructions (R\&D Systems). Plates were read at $450 \mathrm{~nm}$ using the RT-6000 microplate reader (Leidu).

\section{Statistical methods}

The results were expressed as mean \pm standard error of the mean (S.E.M.). The statistical significance of the differences between the treated and control groups were calculated using Student's $t$ test. Results with $P<0.05$ were considered statistically significant. 


\section{Results and discussion}

\section{Hyaluronidase inhibition activity}

In vitro hyaluronidase inhibition activity was used to evaluate the anti-allergic activity of DMY, A. grossedentata, and AEF. The results (Fig. 1) showed that AEF inhibited hyaluronidase activity more effectively than DMY or A. grossedentata. It was concluded that different constituents of the TCM formulation had synergistic interactions, which led to an obvious improvement in anti-allergic activity.

\section{Effect on histamine phosphate-induced pruritus}

AEF significantly increased the histamine phosphate itching threshold in guinea pigs in a dose-dependent manner (Table 1). Allergen-induced itching is sometimes caused by the release of vasoactive substances, such as histamine, from mast cells and basophils. These results showed that AEF had a protective function when applied to the skin, and this could relieve the itching and discomfort associated with sensitive skin.

\section{The PCA reaction in rats}

The anti-IgE antibody-induced PCA has been established as a typical model for a mast cell-dependent immediate-type allergic reaction (Shin et al. 2004). We examined the anti-allergic effects of AEF using a rat PCA model. Local extravasation was induced by a local injection of anti-DNP IgE, followed by an antigenic challenge ( $\mathrm{Lu}$ et al. 2012). PCA was best visualized by the extravasation of dye. Administration of a high dosage of AEF $1 \mathrm{~h}$ prior to antigen injection significantly suppressed the PCA reaction (Table 2). PCA reactioninduced capillary permeability leads to skin inflammation and infiltration, diffuse skin redness, and swelling. AEF produced significant protection from skin allergic and inflammatory injury through inhibition of the PCA reaction.

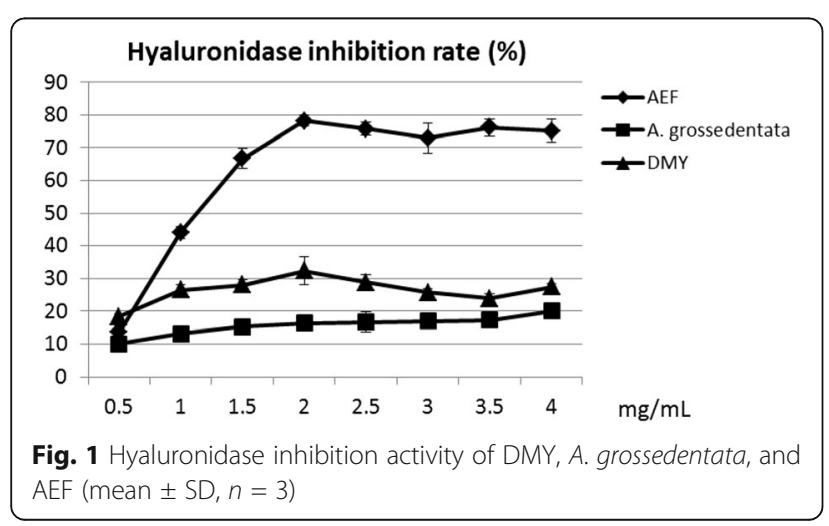

Table 1 The effects of samples on the pruritus response induced by histamine $(x \pm s, n=8)$

\begin{tabular}{llll}
\hline Groups & $\begin{array}{l}\text { Dosage } \\
\left(\mathrm{mg} / \mathrm{cm}^{2}\right)\end{array}$ & $\begin{array}{l}\text { Itching } \\
\text { threshold }(\mu \mathrm{g})\end{array}$ & Inhibition (\%) \\
\hline Model control group & - & $31.67 \pm 2.58$ & \\
DSCG & 100 & $73.21 \pm 12.49^{* *}$ & 131.17 \\
Low dosage & 50 & $62.50 \pm 13.69^{* *}$ & 97.37 \\
Middle dosage & 100 & $85.00 \pm 15.49^{* *}$ & 168.42 \\
High dosage & 150 & $90.00 \pm 16.43^{* *}$ & 184.21 \\
\hline
\end{tabular}

Tips: compared with model control group, ${ }^{* *} P<0.01$

\section{Skin-repairing activity}

When the skin was scratched by acetone to ether $(1: 1)$ solution, the moisture loss was increased to $19.99 \%$ in the model group. High, moderate, and low dosages of AEF significantly decreased this moisture loss and significantly protected the scratched parts of the skin (Table 3). The barrier function of the skin has three elements: the stratum corneum (air-liquid barrier), tight junctions (liquid-liquid barrier), and the Langerhans cell network (immunological barrier) (Kubo et al. 2012). The barrier function is often impaired in sensitive skin, which leads to moisture loss, drying, and itching. The findings of the present study indicated that AEF could contribute to a restoration of skin barrier integrity, thus relieving sensitivity.

\section{Inhibition of IL-6 and IL-8}

DMY was the main chemical constituent of $A$. grossedentata and of AEF $(10.25 \pm 0.83 \mathrm{mg} / \mathrm{g})$. It was reported to inhibit nitric oxide (NO) production in lipopolysaccharide-stimulated RAW264.7 macrophages and to reduce carrageenan-induced acute inflammation in vivo (Kou and Chen 2012). In the present study, basophilic KU812 cells were stimulated with PMA and the calcium ionophore, A23187. The levels of the pro-inflammatory cytokines, IL-6 and IL-8, in stimulated KU812 cells were measured by ELISA. DMY produced a significant dose-dependent reduction in the levels of IL- 6 and IL- 8 in media conditioned by this cell line (Table 4 ).

Table 2 Influence of PCA reaction

\begin{tabular}{llll}
\hline Groups & $\begin{array}{l}\text { Dosage } \\
\left(\mathrm{mg} / \mathrm{cm}^{2}\right)\end{array}$ & $\begin{array}{l}\text { Amount of dye } \\
(\mu \mathrm{g} / \mathrm{mL})\end{array}$ & Inhibition (\%) \\
\hline Blank control group & - & $3.65 \pm 0.46$ & - \\
Model control group & 100 & $144.32 \pm 7.74^{\# \#}$ & - \\
Fluocinonide ointment & 50 & $130.25 \pm 5.14^{*}$ & 9.75 \\
Low dosage & 25 & $139.97 \pm 7.22$ & 3.02 \\
Middle dosage & 50 & $137.18 \pm 4.98$ & 4.95 \\
High dosage & 100 & $128.61 \pm 12.34^{*}$ & 10.89
\end{tabular}

Tips: compared with blank control group, ${ }^{\# \#} P<0.01$; compared with model control group, ${ }^{*} P<0.05$ 
Table 3 The skin repairing effects of samples $(x \pm s, n=8)$

\begin{tabular}{llll}
\hline Groups & Dose $\left(\mathrm{mg} / \mathrm{cm}^{2}\right)$ & Moisture loss & Protection rate (\%) \\
\hline Blank control group & - & $39.08 \pm 6.51$ & - \\
Model control group & 100 & $19.25 \pm 3.14^{\# \#}$ & - \\
Low dosage & 50 & $16.04 \pm 0.61^{* *}$ & 19.79 \\
Moderate dosage & 100 & $14.22 \pm 0.67^{* *}$ & 28.90 \\
High dosage & 150 & $13.87 \pm 0.47^{* *}$ & 30.62 \\
\hline
\end{tabular}

Tips: compared with blank control group, ${ }^{\# \#} P<0.01$; compared with model control group, ${ }^{* * P}<0.01$

Mast cells and basophils are known to play a central role in inflammatory, allergic, and immune events (Galli 1993). Activation of these cells results in degranulation, accompanied by the production of chemical mediators, such as histamine, proteases, metabolites of arachidonic acid, and several inflammatory and chemotactic cytokines, including IL-6, IL-8, IL-1 $\beta$, and tumor necrosis factor (TNF)- $\alpha$. These molecules act on the vasculature and skin, resulting in the recruitment of activated immune and inflammatory cells to the site of inflammatory lesions, thereby amplifying and sustaining the inflammatory condition (Nigrovic and Lee 2005). In various studies, pro-inflammatory cytokines IL-6 and IL-8 released during KU812 cell activation were shown to act on the blood vessels and skin, amplifying the inflammatory and allergic response (Choi et al. 2012).

IL-6 is produced by T cells, monocytes, macrophages, and synovial fibroblasts. It promotes the immune response by increasing IgE production and by increasing IL-8 expression. IL-6 is also produced by mast cells and basophils, accumulates locally in the skin, and is associated with delayed hypersensitivity. In type I allergies, antigens such as foods, dust mites, medicines, pollen, and cosmetics were bound to toll receptors on basophils, leading to IL-6, IL-4, and IL-10 release. These cytokines activate immediate hypersensitivity, increasing IgE generation and producing pro-inflammatory effects. IL-8 has potent chemoattractant activity for neutrophils and $\mathrm{T}$ cells. The IL-8 protein is normally secreted at very low levels from non-induced cells, but its production is rapidly induced by a very wide range of stimuli,

Table 4 IL-6 and IL-8 inhibition results of DMY in KU812 cells

\begin{tabular}{|c|c|c|c|c|c|}
\hline Groups & $\begin{array}{l}\text { Dose } \\
(\mu \mathrm{g} / \mathrm{mL})\end{array}$ & IL-6 & $\begin{array}{l}\text { Inhibition } \\
(\%)\end{array}$ & IL-8 & $\begin{array}{l}\text { Inhibition } \\
(\%)\end{array}$ \\
\hline $\begin{array}{l}\text { Blank control } \\
\text { group }\end{array}$ & & - & & $37.0 \pm 0.8$ & \\
\hline $\begin{array}{l}\text { Model control } \\
\text { group }\end{array}$ & & $38.5 \pm 5.2$ & - & $207.0 \pm 40.9$ & - \\
\hline Low dosage & 50 & $32.0 \pm 6.4$ & 11.7 & $182.8 \pm 24.1$ & 16.9 \\
\hline $\begin{array}{l}\text { Moderate } \\
\text { dosage }\end{array}$ & 200 & $29.8 \pm 2.5$ & 28 & $149.1 \pm 25.0$ & 22.6 \\
\hline $\begin{array}{l}\text { High } \\
\text { dosage }\end{array}$ & 300 & $15.5 \pm 1.6^{* *}$ & 50.6 & $102.2 \pm 13.9^{* *}$ & 59.7 \\
\hline
\end{tabular}

Tips: compared with model control group, ${ }^{* * P}<0.01$ encompassing pro-inflammatory cytokines such as TNF$\alpha$ or IL-1, IL-6, bacterial or viral products, and cellular stress (Hoffmann et al. 2002). The chemoattractant activity of IL-8 aggravated local inflammation and extended the development of skin allergy (Rasheed et al. 2009). The results of the present study therefore suggested that DMY and AEF produced protective effects on the acute phase of hypersensitivity, through inhibition of IL-6, and on delayed hypersensitivity, through inhibition of IL-8.

\section{Conclusions}

The TCM formulation comprising A. grossedentata, $S$. divaricata, S. flavescens, A. sinensis, O. japonicus, and $C$. officinalis (3:2:2:1.7:1.2:1.2) has significant potential for the treatment of sensitive skin. The AEF could relieve pruritus of scratched skin, repair diffuse skin redness, and restore the skin barrier function. The anti-allergic activity of AEF may be associated with inhibition of the pro-inflammatory cytokines, IL- 6 and IL- 8 . These results provided an evidence base for the traditional use of $A$. grossedentata and related TCM formulations for the protection of sensitive skin.

\section{Abbreviations}

AEF: An active extract of this formulation; CAMS: Chinese Academy of Medical Science; DMSO: Dimethyl sulfoxide; DMY: Dihydromyricetin;

DNP: Dinitrophenyl; DPPH: 1,1-Diphenyl-2-picrylhydrazyl; DSCG: Disodium cromoglycate; ELISA: Enzyme-linked immune sorbent assay; FBS: Fetal bovine serum; HPLC: High-performance liquid chromatography; HSA: Human serum albumin; IL: Interleukin; IMDM: Iscove's Modified Dulbecco's Medium; IMPLAD: Institute of Medicinal Plant Development; NO: Nitric oxide; PCA: Passive cutaneous anaphylaxis; PMA: Phorbol 12-myristate 13-acetate; PMACl: Phorbol-12-myristate 13-acetate plus the calcium ionophore A23187; TCM: Traditional Chinese medicine; TNF: Tumor necrosis factor

\section{Acknowledgements}

Not applicable.

\section{Funding}

This work was supported by the National Natural Science Foundation of China (31501402).

\section{Availability of data and materials}

The datasets used and/or analyzed during the current study are available from the corresponding author on reasonable request.

\section{Authors' contributions}

HM performed the animal experiment. LL did the cell experiment. XW was a major contributor in writing the manuscript. GL carried out additional analyses and finalized this paper. $C L$ did the extraction experiment. YD designed the experiment. All authors read and approved the final manuscript.

\section{Ethics approval}

Animal protocols were developed in accordance with the institution's

(Beijing Technology and Business University) guidelines for the care and use of laboratory animals and were approved by the local Animal Care and Use Committee.

Consent for publication Not applicable. 


\section{Competing interests}

The authors declare that they have no competing interests.

\section{Publisher's Note}

Springer Nature remains neutral with regard to jurisdictional claims in published maps and institutional affiliations.

\section{Author details}

${ }^{1}$ Beijing Key Laboratory of Plant Resources Research and Development, Beijing Technology and Business University, Beijing 100048, People's Republic of China. ${ }^{2}$ Infinitus (China) Company Ltd., Guangzhou 510665, China.

Received: 23 February 2017 Accepted: 28 August 2017

Published online: 23 October 2017

\section{References}

Choi SJ, Tai BH, Cuong NM, Kim YH, Jang HD. Antioxidative and antiinflammatory effect of quercetin and its glycosides isolated from mampat (Cratoxylum formosum). Food Sci Biotechnol. 2012;21(2):587-95.

Farage MA, Miller KW, Wippel AM, Misery L, Mailbach $H$. Sensitive skin in the United States: survey of regional differences. Fam Med Medic Sci Res. 2013; 112(2):2.

Galli JG. New concepts about the mast cell. N Engl J Med. 1993;328:257-65. Hoffmann E, Dittrich-Breiholz O, Holtmann H, Kracht M. Multiple control of interleukin-8 gene expression. J Leukoc Biol. 2002;72:847-55.

Hu YM, Zhong ZD. Study on effect of Ma Chi Xian extract for the rat foot itch threshold induced by histamine phosphate. Chin J Ethnomed Ethnopharm. 2013;6:34-5.

Jung HS, Kim MH, Gwak NG, Im YS, Lee K, Sohn Y, Choi H, Yang WM. Antiallergic effects of Scutellaria baicalensis on inflammation in vivo and in vitro. J Ethnopharmacol. 2012;141:345-9.

Kakegawa $\mathrm{H}$. Inhibitory effects of some natural products on the activation of hyaluronidase and their antiallrgic actions. Chen Pharm. 1992;40(6):1439-42.

Kou X, Chen N. Pharmacological potential of ampelopsin in Rattan tea. Food Sci Human Wellness. 2012;1:14-8.

Kubo A, Nagao K, Amagai M. Epidermal barrier dysfunction and cutaneous sensitization in atopic diseases. J Clin Invest. 2012;122(2):440-7.

Lin JY, Ji LH. Optimization of flavonoids from Ginkgo Biloba using response surface analysis. J Chin Inst Food Sci Technol. 2013;13(2):83-90.

Liu XY, Deng W, Li L, Meng H, Ren HK, Dong YM. Skin allergy causes, solution way, and development trend of anti-allergic cosmetics. China Cosmet. 2014; $7 \cdot 72-7$

Lu Y, Li Y, Jin M, Yang JH, Li X, Chao GH, Park HH, Park YN, Son JK, Lee E, Chang HW. Inula japonica extract inhibits mast cell-mediated allergic reaction and mast cell activation. J Ethnopharmacol. 2012;43(1):151-7.

Nigrovic PA, Lee DM. Mast cells in inflammatory arthritis. Arthritis Res Ther. 2005; 7:1-11.

Rasheed Z, Akhtar N, Anbazhagan AN, Ramamurthy S, Shukla M, Haqqi TM. Polyphenol-rich pomegranate fruit extract (POMx) suppresses PMACl-induced expression of pro-inflammatory cytokines by inhibiting the activation of MAP Kinases and NF-KB in human KU812 cells. J Inflamm. 2009;6:1-12.

Shin HY, Na HJ, Moon PD, Shin T, Shin TY, Kim SH, Hong SH, Kim HM. Inhibition of mast cell-dependent immediate-type hypersensitivity reactions by purple bamboo salt. J Ethnopharmacol. 2004;91:153-7.

Xu F, Yan S, Wu M, Li F, Sun Q, Lai W, Shen X, Rahhali N, Taieb C, Xu J. Selfdeclared sensitive skin in China: a community-based study in three top metropolises. J Eur Acad Dermatol Venereol. 2012:27(3):370-5.

\section{Submit your next manuscript to BioMed Central and we will help you at every step:}

- We accept pre-submission inquiries

- Our selector tool helps you to find the most relevant journal

- We provide round the clock customer support

- Convenient online submission

- Thorough peer review

- Inclusion in PubMed and all major indexing services

- Maximum visibility for your research

Submit your manuscript at www.biomedcentral.com/submit 